\title{
Growth and study of 4-sulfobenzenaminium potassium dihydrogenphosphate for mechanical, dielectric and photonics applications
}

\author{
E. Vinoth, S. Vetrivel* ${ }^{*}$ S.Gopinath, R.U. Mullai, R. Aruljothi, T. Suresh \\ Raman Research Laboratory, Post Graduate and Research Department of Physics, Government Arts College, Tiruvannamalai, \\ Tamilnadu, 606 603, India
}

\begin{abstract}
This article describes the growth and characterization of 4-sulfobenzenaminium potassium hydrogen phosphate (SPH) sulphanilic acid with potassium dihydrogen phosphate (KDP) doped semi-organic single crystals. The crystal was grown by the slow evaporation method. Examination of the crystalline nature of the sample was carried out by single crystal X-ray diffraction and it confirmed that the sample crystallizes in orthorhombic structure in the centrosymmetric space group P $2{ }_{1} 2_{1} 2_{1}$. The optical transmittance behavior was tested by UV-Vis spectral analysis. FT-IR spectral investigations have been carried out to indicate the presence of functional groups. The chemical structure of the compound was established by ${ }^{1} \mathrm{H}$ and ${ }^{13} \mathrm{C}$ NMR spectra. The SHG efficiency of the powdered SPH crystal is around 1.7 times that of pure KDP. The grown crystal was stable up to $270{ }^{\circ} \mathrm{C}$ as observed from TGA and DTA curves. The microhardness test was carried out to study the load dependency of hardness. The result of this study indicates that SPH crystal is a malleable material. From the hardness values, the stiffness constant and yield strength were calculated. The dielectric response of the novel crystal was studied in the frequency range of $50 \mathrm{~Hz}$ to $5 \mathrm{MHz}$ at various temperatures. By employing FE-SEM, the surface morphology and the particle size of the crystal were assessed.
\end{abstract}

Keywords: slow evaporation; single crystal; NLO; hardness; SHG efficiency; dielectric behavior.

\section{Introduction}

The broad search for new materials with high optical nonlinearity is a hot subject because of the possibility of their application in electro-optic regulation, modulation of frequency mixing, optical registering, laser remote detection, laser fusion reactions and optical information stockpiling [1-4]. In general, organic nonlinear optical (NLO) dynamic crystals have higher nonlinear properties than their inorganic counterparts. It is due to the formation of bonds by strong Coulombic interactions [5]. Developing of a new kind of nonlinear optical materials or enhancing the NLO efficiency of the known materials becomes necessary for the development. High polarization of organic molecule due to its electron donor or acceptor property makes it suitable for NLO application [6]. The aromatic benzene derivatives can

*E-mail: vetrivelsivaraman@yahoo.com produce high molecular nonlinearity. Sulphanilic acid (SAA) is an exceptionally intriguing compound since it has the properties appropriate for medical, biological, NLO and radiation dosimetry applications [7-9]. SAA contains sulfonic acid $\left(-\mathrm{SO}_{3} \mathrm{H}\right)$ and amine functional groups. So it acts as a base which makes a compound through nitrogen (amino) atom. The growth and NLO properties of sulphanilic acid based crystals have been reported in the literature $[10,11]$. The structure of SAA monohydrate crystals is monoclinic in $\mathrm{P} 2{ }_{1} / \mathrm{n}$ system [12], whereas that of SAA methanol crystal is orthorombic in $\mathrm{P} 2{ }_{1}{ }_{1} 2_{1}$ system [13]. The tetrabutyl ammonium 4-aminobenzenesulfonate $2 / 3$ hydrate and lithium sulphate crystal are arranged in monoclinic structure in the $\mathrm{P} 2{ }_{1} / \mathrm{c}$ system [14, 15]. The piperazine 1-4-diium bis (4-aminobenzene sulphonate) crystals are of orthorhombic structure in Pbca system [16]. The sodium carbonate with SAA based crystal structure appears in orthorhombic structure 
and belongs to the Pca21 space group [17]. Bis-(4-aminobenzenesulfonato-N) bis (2,2-biimidazole-N, N) copper(II)dihyrate crystallizes in triclinic structure is in the $\mathrm{P}^{1}$ space group [18].

In this investigation, a novel organic SPH crystal has been grown from an aqueous solution. The grown crystal was characterized by FT-IR, UV-Vis, $\mathrm{X}$-ray diffraction, NMR, thermal, nonlinear optical and dielectric studies. The obtained results have been interpreted and reported in this article and have not been published anywhere yet.

\section{Experimental}

\subsection{Materials and methods}

Sigma-Aldrich brand potassium dihydrogen phosphate and Merck brand sulphanilic acid were used in this work. The single crystal X-ray diffraction data of STA crystal were recorded by Nonius CAD4/MACH3 single crystal X-ray diffractometer with $\mathrm{MoK} \alpha$ radiation $(\lambda=71023 \AA)$. Alpha Bruker FT-IR spectrophotometer with a resolution of $2 \mathrm{~cm}^{-1}$ was employed to record infrared spectra. The samples were prepared by $\mathrm{KBr}$ pellet method and the experiment was carried out at room temperature. ${ }^{1} \mathrm{H}$ and ${ }^{13} \mathrm{C}$ NMR spectra of the crystals were recorded on a Bruker FT-NMR spectrophotometer working at $400 \mathrm{MHz}$ at room temperature with dimethylmethoxide (DMSO) as a solvent and tetramethylsilane (TMS) as an internal reference. The thermal stability of the crystal was examined by thermogravimetric analysis (TGA) using Dupont 951 thermogravimertic analyzer. $8 \mathrm{mg}$ to $10 \mathrm{mg}$ weight sample was used. The test was performed in the temperature range of 30 to $600{ }^{\circ} \mathrm{C}$ at the heating rate of $10{ }^{\circ} \mathrm{C} \mathrm{min}-1$ in a nitrogen atmosphere with a gas flow rate of $100 \mathrm{ml} \cdot \mathrm{min}^{-1}$. The surface morphologies and particle sizes of the sample were determined by field emission scanning electron microscopy (FE-SEM; Hitachi S4800; Japan).

\subsection{Growth of the metal based novel SPH crystals}

The novel crystal of SPH was grown by slow evaporation technique. A mixture solution of SAA

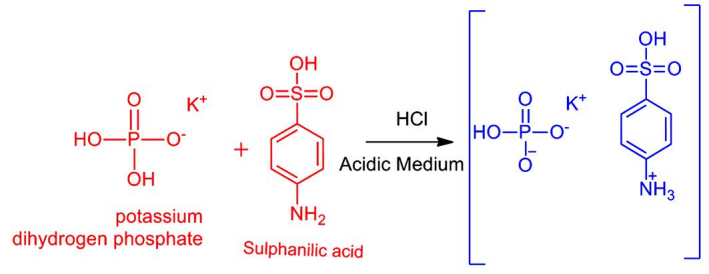

Fig. 1. Scheme of growth of SAA with KDP doped novel SPH crystal.

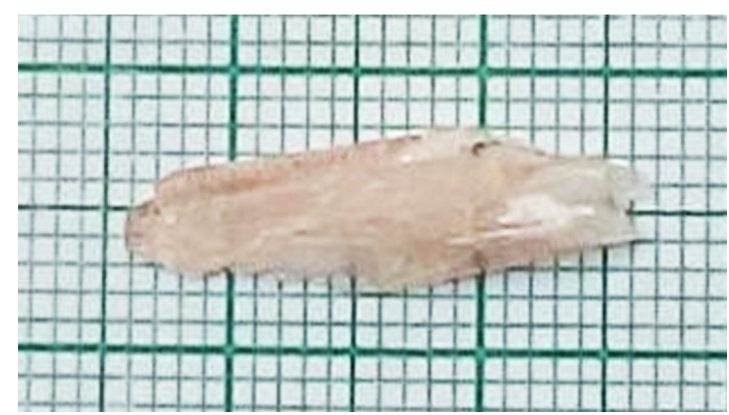

Fig. 2. Photograph of SPH crystal.

with KDP in equivalent mole proportion was prepared. The required amount of SAA was first dissolved in Millipore water of $18.2 \mathrm{M} \Omega \cdot \mathrm{cm}^{-1}$ resistivity. KDP was independently dissolved in water and added gradually into the solution of sulphanilic acid. It was mixed well using a temperature controlled magnetic stirrer for around 10 hours to obtain a homogenous mixture. The stirred solution was filtered with Whatmann filter paper and permitted to evaporate at room temperature. Purification of the grown crystal was achieved by recrystallization process. Good quality single crystals were grown at the rate of $0.28 \mathrm{~mm} /$ day and harvested with average size of $25 \mathrm{~mm} \times 10 \mathrm{~mm} \times 3 \mathrm{~mm}$. The synthesis route of SAA with KDP doped novel SPH crystal is shown in Fig. 1 and the growth parameters are presented in Table 1. The photograph of as-grown SPH a crystal is shown in Fig. 2.

\section{Results and discussion}

\subsection{Single crystal XRD}

The grown crystal was subjected to single crystal X-ray diffraction analysis. The obtained 
Table 1. Growth parameters.

\begin{tabular}{ccccccccc}
\hline $\begin{array}{l}\text { S. No. Crystal Mole fraction Molecular Period of } \\
\text { code }\end{array}$ & SAA & KDP & Size of the & \multicolumn{2}{c}{ Color of the Rate of growth } \\
growth & crystal $\left[\mathrm{mm}^{3}\right]$ & crystal & {$\left[/ \mathrm{mm}^{3}\right]$} \\
\hline \hline 1 & SPH & 1 & 1 & 309 & 50 & $25 \times 10 \times 3$ & Colorless & 0.28 \\
\hline
\end{tabular}

crystallographic information is given in Table 2 . From the data, it is observed that the crystal parameters of the grown SPH differ from that of pure SAA and pure KDP. The lattice parameters acquired are $\mathrm{a}=6.49 \AA, \mathrm{b}=9.649 \AA, \mathrm{c}=13.36 \AA$, $\alpha, \beta$ and $\gamma=90^{\circ}$ and $\mathrm{V}=837 \AA^{3}$. It crystallizes in orthorhombic structure in the space group $\mathrm{P} 2{ }_{1} 2_{1} 2_{1}$. This confirms the formation of new crystal.

\subsection{FT-IR spectral studies}

A chemical compound has various functional groups which could be identified by FT-IR spectrum. The FT-IR spectrum of SPH crystal recorded in the wave number range of $500 \mathrm{~cm}^{-1}$ to $4000 \mathrm{~cm}^{-1}$ is shown in Fig. 3 .

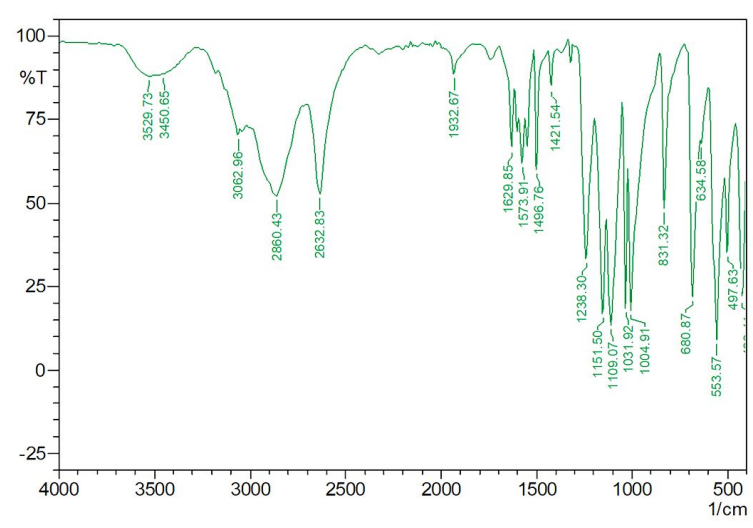

Fig. 3. FT-IR spectrum of SPH crystal.

Table 3 gives the information of various functional groups. A peak at $3529 \mathrm{~cm}^{-1}$ is assigned to the $\mathrm{O}-\mathrm{H}$ stretching frequency of dihydrogen phosphate. The absorbance peak at $2632 \mathrm{~cm}^{-1}$ is caused by the presence of $\mathrm{N}-\mathrm{H}-\mathrm{O}$ stretching vibrations [21]. The peak appearing at $3062 \mathrm{~cm}^{-1}$ is due to $\mathrm{C}-\mathrm{H}$ vibrations. The peak at $3450 \mathrm{~cm}^{-1}$ is assigned to $\mathrm{N}-\mathrm{H}$ vibrations which indicate all the $\mathrm{NH}_{2}$ changed into $\mathrm{N}-\mathrm{H}$ in the lattice.

$\mathrm{CH}$ stretching vibration causes a peak at $2860 \mathrm{~cm}^{-1}$. The peak appearing at $1629 \mathrm{~cm}^{-1}$ is assigned to $-\mathrm{NH}_{3}^{+}$anilinium moiety. The peak appearing at $1031 \mathrm{~cm}^{-1}$ is caused by asymmetric stretching frequency of $\mathrm{C}-\mathrm{N}$. The characteristic peak observed at $1238 \mathrm{~cm}^{-1}$ is assigned to $\mathrm{S}=\mathrm{O}$ stretching vibration due to sulphonate group. The benzene ring skeletal vibration peaks of SAA appear at $1573 \mathrm{~cm}^{-1}, 1496 \mathrm{~cm}^{-1}$ and $1421 \mathrm{~cm}^{-1}$. The peaks at $1151 \mathrm{~cm}^{-1}$ and $1109 \mathrm{~cm}^{-1}$ are assigned to symmetric and asymmetric frequency of $\mathrm{SO}_{3}^{-}$ group vibrations. $\mathrm{N}-\mathrm{H}$ stretching results in peaks at $680 \mathrm{~cm}^{-1}$ and $634 \mathrm{~cm}^{-1}$.

\subsection{UV-Vis spectral analysis}

UV-Vis spectroscopy is a method based on absorption of light by a molecule. The light energy absorbed is used to excite electrons from the ground state to higher energy state. The energy of the ultraviolet radiation that is absorbed is equal to the energy difference between the ground state and higher energy states. Generally, the most favored transition is from the highest occupied molecular orbital (HOMO) to the lowest unoccupied molecular orbital (LUMO). For most of the molecules, the lowest energy occupied molecular orbitals are s orbitals, which correspond to sigma bonds. The p orbitals are at somewhat higher energy levels, the orbitals (nonbonding orbitals) with unshared paired electrons lie at higher energy levels. The unoccupied or antibonding orbitals (pie* and sigma*) are the highest energy occupied orbitals. In all the compounds (other than alkanes), the electrons undergo various transitions. Some of important transitions with increasing energies are: non-bonding to pie*, $^{*}$ non-bonding to sigma*, pie to pie*, sigma to pie $^{*}$ and sigma to sigma*. This UV-Vis spectral studies help to analyse the factors connected with a crystal such as anisotropy in molecular alignment, crystal defects (voids, vacancies, grain boundaries, striations, pits, solvent impurities, inclusions) by measuring the intensity of optical transmittance [32]. 
Table 2. Comparison of crystallographic data of SPH, SAA and KDP.

\begin{tabular}{llll}
\hline Parameter & $\mathrm{SAA}^{*}$ & $\mathrm{KDP}^{\#}$ & $\mathrm{SPH}$ \\
\hline \hline Chemical formula & $\mathrm{C}_{6} \mathrm{H}_{7} \mathrm{NO}_{3} \mathrm{~S} \cdot \mathrm{H}_{2} \mathrm{O}$ & $\mathrm{KH}_{2} \mathrm{PO}_{4}$ & $\mathrm{C}_{6} \mathrm{H}_{9} \mathrm{KNO}_{7} \mathrm{PS}$ \\
Molecular weight $\left[\mathrm{g} / \mathrm{cm}^{3}\right]$ & 191.2 & 136 & 309.28 \\
$\mathrm{a}[\AA]$ & 6.16 & 7.49 & 6.49 \\
$\mathrm{~b}[\AA]$ & 6.96 & 7.49 & 9.64 \\
$\mathrm{c}[\AA \AA$ & 6.91 & 13.36 \\
$\alpha$ & 18.32 & $90^{\circ}$ & $90^{\circ}$ \\
$\beta$ & $90^{\circ}$ & $90^{\circ}$ & $90^{\circ}$ \\
$\Gamma$ & $90^{\circ}$ & $90^{\circ}$ & $90^{\circ}$ \\
$\mathrm{V}\left[\AA^{3}\right]$ & $90^{\circ}$ & 392 & 837 \\
Crystal system, & 786 & Tetragonal & Orthorombic \\
Space group & Orthorhombic & $\mathrm{I} 42 \mathrm{~d}$ & $\mathrm{P} 2_{1} 2_{1} 2_{1}$ \\
Crystal size $\left[\mathrm{mm}^{3}\right]$ & $0.25 \times 0.22 \times 0.2$ & - & $25 \times 10 \times 3$ \\
Color & Pale yellow & Colorless & Colorless \\
Reflection & 0.39 & 0.137 & 0.42 \\
\hline
\end{tabular}

Table 3. The functional group and vibrational assignments of SPH crystal.

\begin{tabular}{cc}
\hline IR $\left[\mathrm{cm}^{-1}\right]$ & Assignment \\
\hline 3529 & $\mathrm{O}-\mathrm{H}$ \\
3450 & $\mathrm{~N}-\mathrm{H}$ \\
3062 and 2860 & $\mathrm{C}-\mathrm{H}$ stretching \\
2632 & $\mathrm{~N}-\mathrm{H}-\mathrm{O}$ \\
1629 & $\mathrm{NH}_{3}^{+}$stretching \\
1573,1496 and 1421 & $\mathrm{C}=\mathrm{C}$ ring skeletal vibrations \\
1847,1614 and 1511 & $\mathrm{C}-\mathrm{C}$ stretching \\
1209 & $\mathrm{C}-\mathrm{N}$ stretching \\
1238 & $\mathrm{~S}=\mathrm{O}$ vibration \\
1151 and 1109 & $\mathrm{~N}-\mathrm{H}$ stretching \\
680 & $\mathrm{SO}_{3}^{-}$symmetric and asymmetric frequency \\
\end{tabular}

An optical absorption spectrum recorded in the UV-Vis spectral range is displayed in Fig. 4. From the spectrum, it is revealed that KDP doped SA crystals have a wider transmission range with lower cut off wavelength at $300 \mathrm{~nm}$. Nonlinear optical material can be of practical use only if it has a wide transparency window $[22,29]$. The absorption band at the wavelength $247 \mathrm{~nm}$ might be due to a $\pi \rightarrow \pi^{*}$ transition of the phenyl ring moiety of SPH crystal.

\section{4. $\quad{ }^{1} \mathrm{H}$ and ${ }^{13} \mathrm{C}$ NMR studies}

${ }^{1} \mathrm{H}$ and ${ }^{13} \mathrm{C}$ NMR spectra are pictured in Fig. 5 and chemical shifts are represented in Table 4. A chemical shift at $\delta=7.0$ to $8.8 \mathrm{ppm}$ in ${ }^{1} \mathrm{H}$ NMR spectrum confirms the presence of resonance of aromatic hydrogen. The sharp singlet at $\delta=$ $4.7 \mathrm{ppm}$ is due to the presence of $-\mathrm{NH}_{3}^{+}$group. The sharp intensive resonance peak signals of $-\mathrm{NH}_{3}^{+}$of 


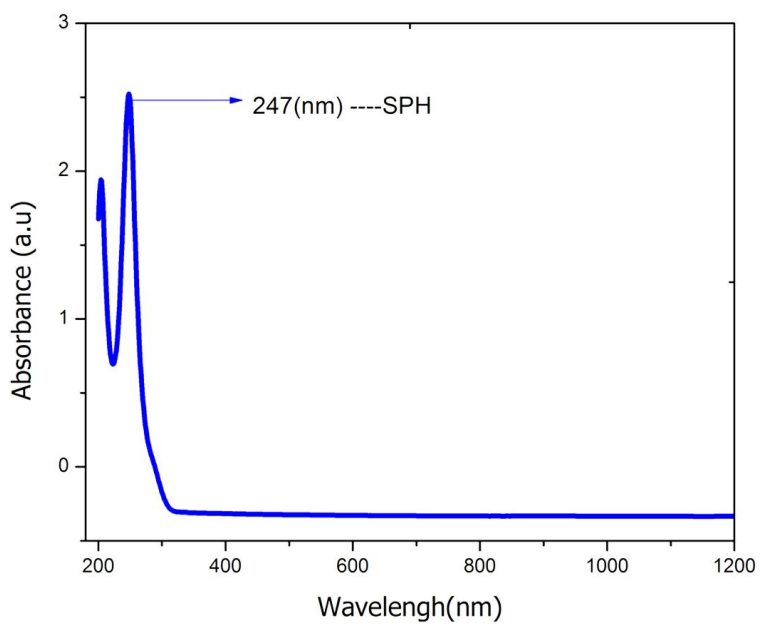

Fig. 4. UV-Vis spectrum of SPH crystal.

anilinium substution appear at $4.3 \mathrm{ppm}$ [23]. The multiplet at higher field range $\delta=7.3$ to 7.8 affirms the aromatic proton of anilinium ion $[24,25]$. The above results establish the structure of the grown crystal.

The ${ }^{13} \mathrm{C}$ NMR spectrum demonstrates the resonance signals of aromatic carbons appearing in the range of $119 \mathrm{ppm}$ to $163 \mathrm{ppm}$. A signal appearing at $\delta=147$ is allocated to the carbon atom of $\mathrm{C}_{2}$ and $\mathrm{C}_{6}$ and the medium intensity peak at $119 \mathrm{ppm}$ is attributed to $\mathrm{C}_{3}$ and $\mathrm{C}_{5}$ carbon atoms of sulphanilic moiety. The SPH crystal moiety appears as resonance signal at $147 \mathrm{ppm}$ due to $\mathrm{C}_{1}$ and $\mathrm{C}_{4}$ carbon bearing $\left(\mathrm{SO}_{3}\right.$ and $\left.\mathrm{NH}_{2}\right)$.

\subsection{NLO studies}

The second harmonic generation effectiveness of SPH crystal was evaluated by Kurtz powder technique. The sample was exposed to a Qswitched Nd:YAG laser emitting $1064 \mathrm{~nm}$ at $10 \mathrm{~ns}$ pulse width and $5 \mathrm{~mJ}$ power. A detector connected to a control unit was used to measure the second harmonic intensity and study the input and output energy. From SHG test, the SHG efficiency of the synthesized SPH crystal was found to be almost 1.7 times more than that of the reference KDP. The enhancement of SHG efficiency results from (i) an incresease in electron phonon interactions by structural disordering in a crystal that leads to the formation of a sub-energy bands below the energy gap
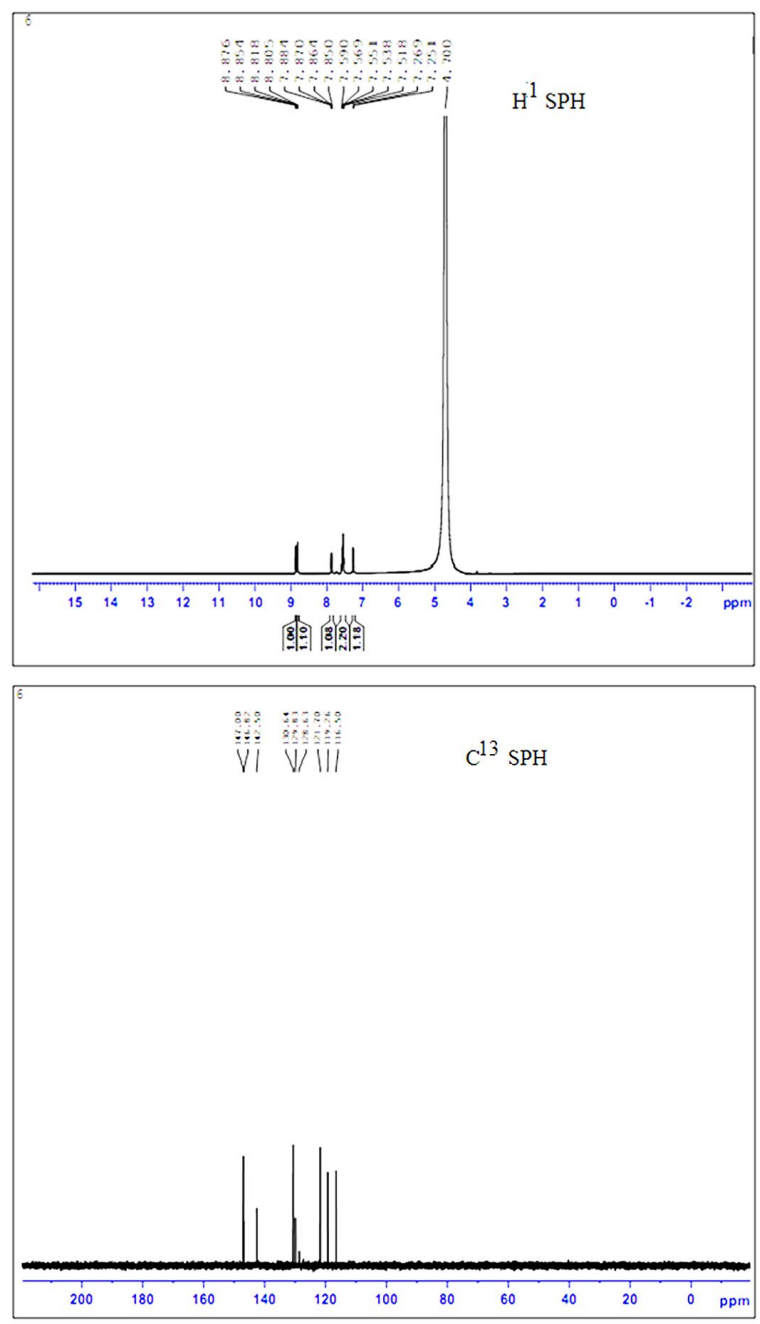

Fig. 5. ${ }^{1} \mathrm{H}$ and $\mathrm{C}^{13} \mathrm{NMR}$ spectra of SPH crystals.

and thus facilitates the favorable surroundings for photoinduced nonlinear optical effects to dwell efficiently and (ii) the enhanced charge transfer induced by the metal-organic coordination $[32,33]$.

\subsection{Thermal studies}

Thermal stability of the grown single crystal SPH was assessed by TGA/DTA method. The TGA/DTA thermogram of the SPH is visualized in Fig. 6. The DTA curve of SPH demonstrates the endothermic peaks at $193{ }^{\circ} \mathrm{C}$ and $276{ }^{\circ} \mathrm{C}$. The hygroscopic nature of the crystal can be ascertained by the presence of a peak around $100{ }^{\circ} \mathrm{C}$. As there is no such peak observed in this case, the crystal is not hygroscopic in nature. The grown crystal 
Table 4. NMR Chemical shifts of SPH crystal.

\begin{tabular}{cccc}
\hline Sample & Spectrum & Signals at $\delta \mathrm{ppm}$ & Group identification \\
\hline \hline SPH & ${ }^{1} \mathrm{H}$ & 4.7 & H-N-C-aromatic protons \\
& & $7.0-7.6$ & Aromatic protons \\
& ${ }^{13} \mathrm{C}$ & 121 & Aromatic carbon \\
& & 116 & Aromatic carbon \\
& & 147 & $\mathrm{C}=\mathrm{S}$ carbon \\
\hline
\end{tabular}

demonstrates a slight thermal degradation up to $330{ }^{\circ} \mathrm{C}$. It means that $\mathrm{SPH}$ crystal possesses good thermal stability.

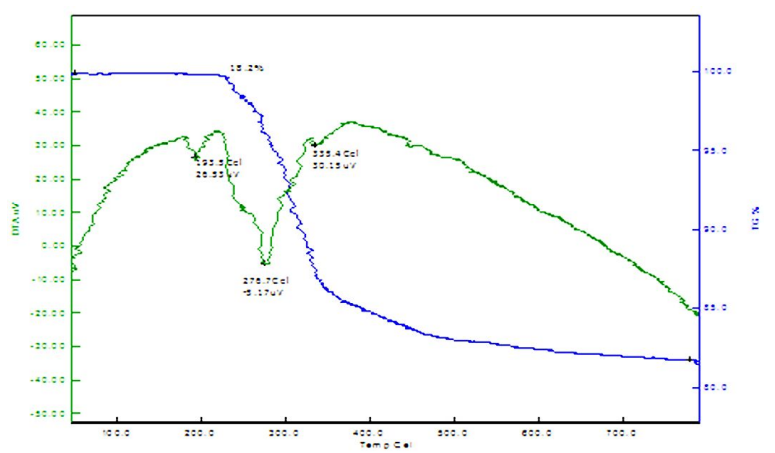

Fig. 6. TG-DTA curves of SPH crystal.

\subsection{Dielectric studies}

Dielectric properties play a key role in different phenomena in gadgets, optical and solid state physics. The dielectric study enables to understanding the variation of dielectric constant and this information is very useful in designing supercapacitors which are frequently used in above said applications. So, it is mandatory to examine the dielectric properties of any material, such as storage and dissipation of electric and magnetic energy [26]. The dielectric constant and the dielectric loss of the SPH single crystals were studied with the help of a LCR meter, HIOKI HITESTER model 3532-50. The excellent silver glue was used to make electrodes on both sides. The dielectric constant and dielectric loss have been calculated using equation 1 and equation 2:

$$
\varepsilon=\frac{c d}{A \varepsilon o}
$$

$$
\varepsilon=\varepsilon \tan \delta
$$

where $\mathrm{d}$ is the thickness and $\mathrm{A}$ is the area of the sample. The frequency dependent dielectric constant and dielectric loss as a function of frequency is shown in Fig. 7 and Fig. 8. From the graphs it is noticed that the values of dielectric constant and dielectric loss are reducing with rising frequency and increasing with the rising temperature. The dielectric constant is high at low frequency due to different types of polarization, namely charge polarization, bipolar, van der Waals force, hydrogen bonds, electronic, ionic, atomic, space charge, and so on.

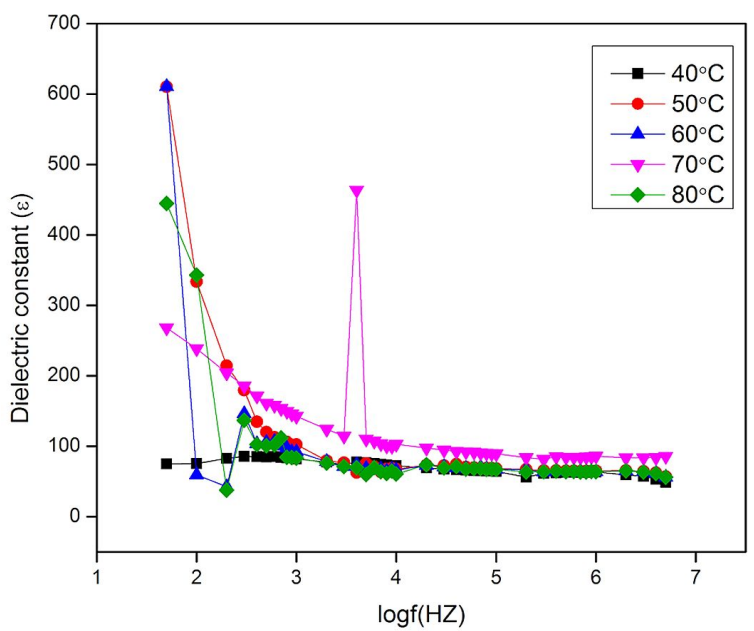

Fig. 7. Variation of dielectric constant with log frequency for SPH crystal.

The peaks appearing in the graphs may be due to two factors:

(1) dehydration of water molecules.

(2) structural changes in the grown material.

But from the thermal studies as there are no water molecules, the peak is only due to the structural changes in the crystal. The dielectric loss 
factor $(\tan \delta)$ is proportional to the conductivity and is equal to the energy needed for dipole ordering. With increasing frequency, the dipoles cannot follow the rate of changes, so that they react to such fields more weakly. The loss factor increases with increasing temperature $[34,35]$. Polarization develops in the material exposed to electric field. The large dielectric constant at low frequency is due to the presence of space charge polarization [27]. The low value of dielectric loss at high frequencies suggests high optical quality of the crystal with lesser defects, which is the desirable property for optical applications [28].

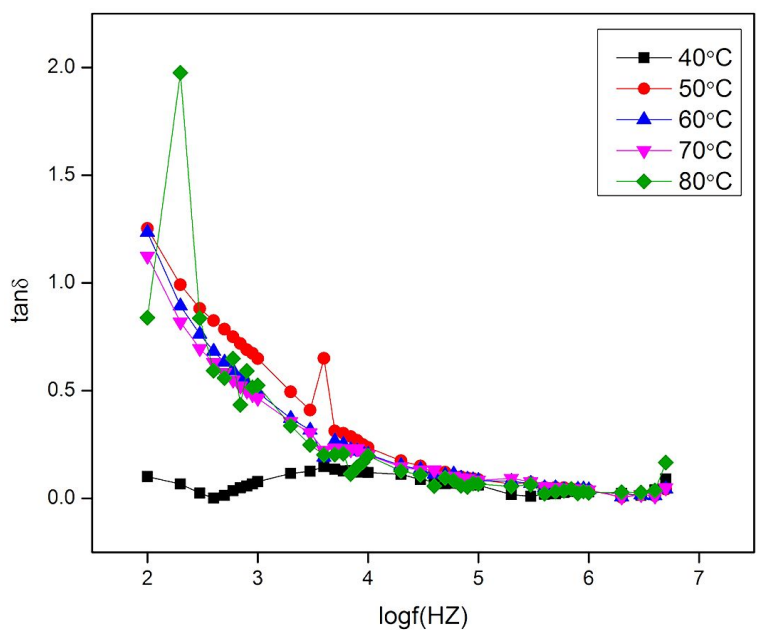

Fig. 8. Variation of dielectric loss with log frequency for SPH crystal.

\subsection{Microhardness}

The structure and composition of crystalline solids can be studied by mechanical examinations [29]. The Vickers hardness is the most important factor used in choosing, preparing (cutting, grinding and polishing) and fabrication of crystals in gadgets. The quickest and simplest sort of mechanical testing is the Vickers microhardness test. Among different testing strategies utilized for measurement of factors such as crack length, fracture toughness, brittle index and elastic stiffness, Vickers hardness test technique is used for testing local deformation. The microhardness measurements were performed in SPH crystal. The applied load (P) ranged from $25 \mathrm{~g}$ to $100 \mathrm{~g}$ for a constant indentation time of $10 \mathrm{~s}$ and the diagonal length (d) of the indentation was measured.

The Vickers hardness value is calculated using the formula $\mathrm{H}_{v}=1.8544 \mathrm{P} / \mathrm{d}^{2}\left(\mathrm{Kg} / \mathrm{mm}^{2}\right)$. A graph was plotted between $\mathrm{H}_{v}$ versus load $(\mathrm{P})$ and it is shown in Fig. 9a. For an indentation load of $100 \mathrm{~g}$, crack was initiated on the crystal surface, around the indent. This is caused by the release of internal stress initiated by indentation. The work hardening coefficient $n$ has been computed from the slope of a straight line between $\log \mathrm{P}$ and $\log$ d shown in Fig. 9b and it was found to be 2.9, which demonstrates moderately soft nature of material [30]. The yield strength of the material can be expressed by the relation [31]:

$$
\sigma y=\frac{H v}{3}(0.1) n-2
$$

where $\mathrm{y}$ is the yield strength of the material, $\mathrm{Hv}$ is the hardness number and $\mathrm{n}$ is the work hardening coefficient. The graph drawn for yield strength versus load $\mathrm{P}$ is shown in Fig. 9c. It is seen that yield strength increases with load, and it is concluded that the grown crystal has moderately high mechanical strength. As indicated by Wooster, the stiffness constant (C11) for SPH single crystal can be found by the relation $\mathrm{C} 11=\mathrm{Hv}^{7 / 4}$.

A graph is plotted between load $\mathrm{P}$ and stiffness constant as presented in Fig. 9d. An increase in stiffness constant with load is observed. The calculated stiffness constant $\mathrm{C} 11$, yield strength $\sigma_{\mathrm{y}}$ and Vickers hardness value for different loads are compiled in Table 5.

\subsection{FE-SEM}

The surface morphology and the particle size of the crystal were assessed through FE-SEM examination and the outcomes are indicated in Fig. 10. From the figure, it is seen that the potassium phosphate particles are clustered on the surface of the SPH crystal.

\section{Conclusion}

SPH crystal has been successfully grown by the slow evaporation method. Single crystal XRD analysis revealed that the crystal belongs 


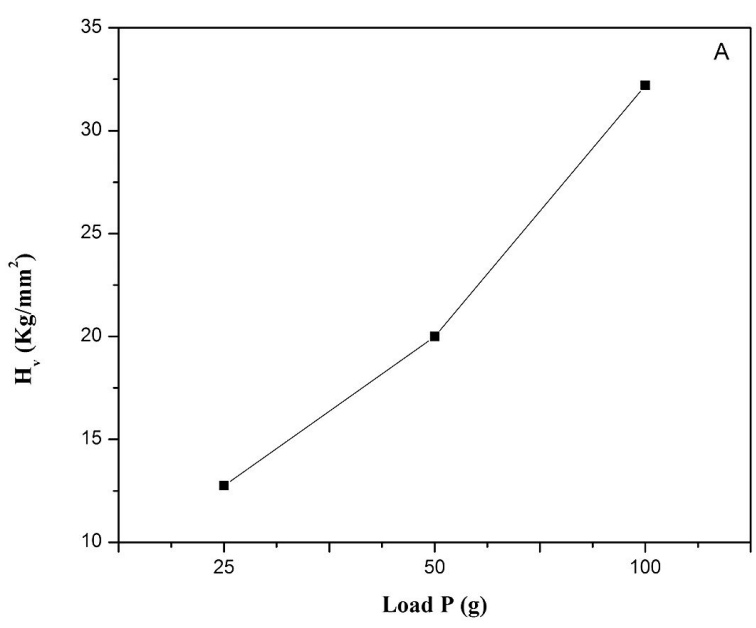

(a)

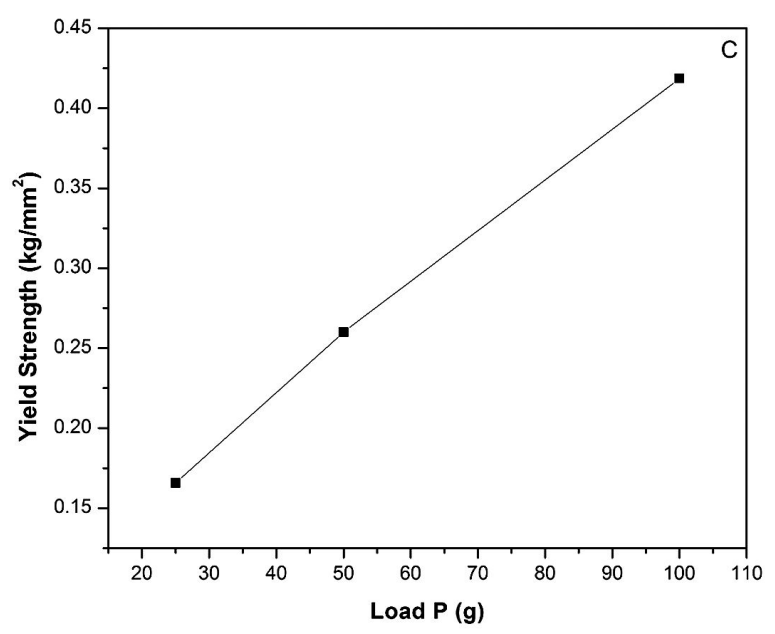

(c)

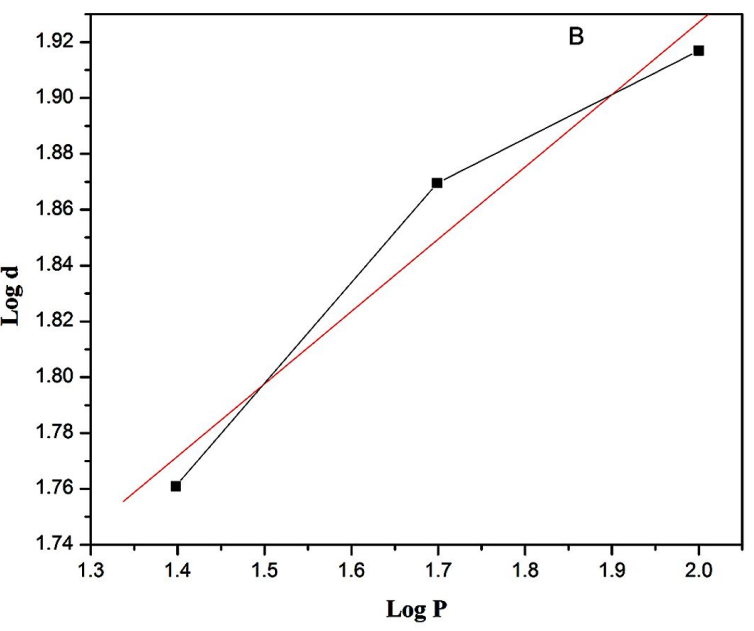

(b)

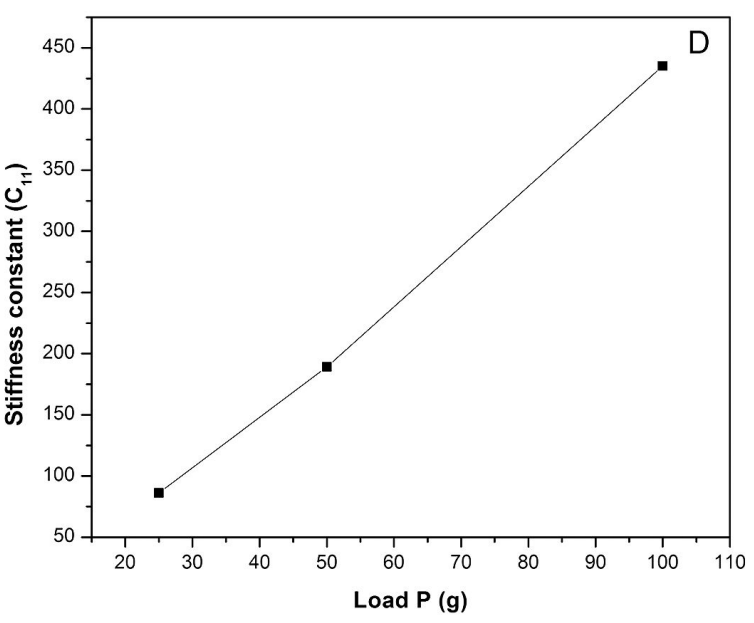

(d)

Fig. 9. (a) Hardness number; (b) plot of $\operatorname{logd}$ vs. $\log P$; (c) yield strength; (d) stiffness constant.

Table 5. Mechanical parameters of SPH crystal.

\begin{tabular}{ccccccc}
\hline $\begin{array}{c}\text { Load } \mathrm{P} \\
{[\mathrm{g}]}\end{array}$ & $\begin{array}{c}\mathrm{H}_{\mathrm{v}} \\
\mathrm{Kg} / \mathrm{mm}^{2}\end{array}$ & $\mathrm{D} \mu \mathrm{m}$ & $\begin{array}{c}\text { Yield } \\
\text { strength } \\
{\left[\sigma_{\mathrm{y}}\right]} \\
\mathrm{Kg} / \mathrm{mm}^{2}\end{array}$ & $\begin{array}{c}\text { Elastic } \\
\text { stiffness } \\
\text { constant } \\
\left(\mathrm{C}_{11}\right)\end{array}$ & $\begin{array}{c}\text { Fracture } \\
\text { toughness } \\
\left(\mathrm{K}_{\mathrm{c}}\right) 10^{4} \\
\mathrm{~kg} / \mathrm{m}^{3 / 2}\end{array}$ & $\begin{array}{c}\text { Brittleness } \\
\text { index }(\mathrm{Bi}) \\
\mathrm{m}^{-1 / 2}\end{array}$ \\
\hline \hline 25 & 12.75 & 57.66 & 0.16 & 86.02 & 2.30 & 552.73 \\
50 & 20.00 & 74.06 & 0.25 & 189.14 & 3.16 & 630.97 \\
100 & 32.20 & 82.59 & 0.41 & 435.25 & 5.38 & 598.13 \\
\hline
\end{tabular}

to orthorhombic structure in the space group the formation of functional groups, vibration peaks $\mathrm{P} 2{ }_{1} 2_{1} 2_{1}$. The optical behavior was examined by and arrangement of hydrogen bond $\mathrm{N}-\mathrm{H}-\mathrm{O}$ in the UV-Vis spectra and the lower cutoff wavelength SPH crystal. The chemical structure and molecular of $247 \mathrm{~nm}$ was found. The FT-IR spectra revealed arrangement of the grown crystal were established 


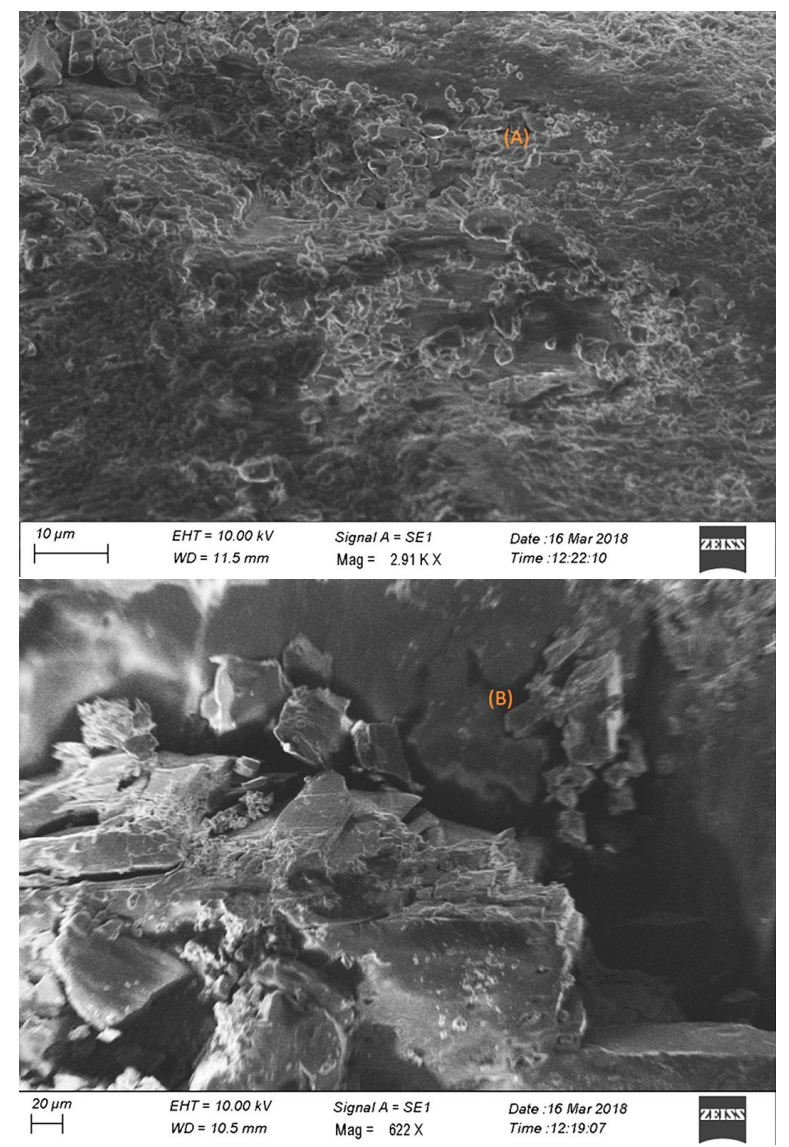

Fig. 10. FE-SEM image of KDP doped SPH crystal.

by ${ }^{1} \mathrm{H}$ and ${ }^{13} \mathrm{C}$ NMR spectra. The SHG productivity of the powdered $\mathrm{SPH}$ is around 1.7 times that of pure KDP. The thermal behavior of the grown crystal has been examined and the melting point was found at $276{ }^{\circ} \mathrm{C}$. The crystal was stable up to $330{ }^{\circ} \mathrm{C}$. The crystal shows the normal dielectric behavior. The Vickers microhardness study showed the soft nature of the material. The surface morphology and the particle size of the crystal were assessed through FE-SEM examinations.

\section{References}

[1] Madurambal G. Mariyappan M., Majumdar S., Therm. Anal. Calorim., 100 (2010), 853.

[2] Chemla D.S., Zyss J. (Eds), Nonlinear Optical Properties of Organic Materials, Springer, Berlin, 1987.

[3] PRASAD P.N., Williams D.J., Introduction to Nonlinear optical effects in organic molecules and polymers, Wiley-Interscience, New York, 1991.

[4] Rajasekaran R., Ushashree P.M., JayaVel R. RAMASAMY P., J. Cryst. Growth, 229 (2001), 563.
[5] Jin S., WANG D., HuAng Y., FAng H., WANG T., Fu P., Ding L., J. Mol. Struct., 1017 (2012), 51.

[6] Arjunan V., Mariusz K., Marchewka K., Pietraszko A., Kalaivan M., Spect. Acta Part A, 97 (2012), 625.

[7] Jiang M.H., FAng Q., Adv. Mater., 11 (1999), 1147.

[8] Hanumantharao R., Kalainathan S., Spectrochim. Acta A, 86 (2012), 80.

[9] Roskar M.J., Cunningham P., Ewbank M.D., Marcy H.O., VAChSS F.R., WARREN L.F., GAPPINGER R., BorWiCK R.., Pure Appl. Opt., 5 (1996), 667.

[10] Long N.J., Angew. Chem. Int. Ed., 34 (1995), 21.

[11] Kurtz S.K., Perry T.T., J. Appl. Phys., 39 (1968), 3798.

[12] Rae A.I.M., Maslen E.N., Acta Cryst. 15 (12) (1962), 1285.

[13] Banu A., Hossain G.M., Acta Cryst. Sec. E, 62 (2006), 02252.

[14] CAI Y., Sun N., Z. Kristallogr., 231 (3) (2016), 23.

[15] Boopathi K., Rajesh P., Ramasamy P., J. Cryst. Growth, 1 (15) (2012), 1.

[16] Sathesh Kumar K., Ranjith S., Sudhakar S., Srinivasan P., Ponnuswamy M.N., Acta Crystallogr. E Crystallogr. Commun., 71 (2015), 1084.

[17] Mythili P., Kanagasekaran T., Sharma Shailesh N., Gopalakrishnan R., J. Cryst. Growth, 306 (2007), 344.

[18] LiU B., YAng W., DaI Y.-C., Zhou L.-L., Jin Q.-H., ZHANG C.-L., Z. Kristallogr., 228 (2013), 229.

[19] Shakir M.V., Ganesh B., Riscob K.K., MaUrya K., Kishan RaO M.A., Bhagavannarayana G., Int. J. Pure Appl. Phys., 7 (2011), 13.

[20] Babu A.G., Bhagavannarayana G., J. Cryst. Growth, 310 (2008), 2820.

[21] Caroline L.M, Mani G., Kumaresan S., Kumar M., Selvan T.S., Optoelectron. Adv. Mater., 9 (2015), 1239.

[22] Rajalakshmi M., Indirajith R., Palanichamy M., Gopalakrishnan R., Spectrochim, Acta Part A, 84 (2011), 43.

[23] Dhanalakshmi B., Ponnusamy S., Muthamizhchelvan C., Subhashini V., $J$. Cryst. Growth, 426 (2015), 103.

[24] Subhashini V., Ponnusamy S., Muthamizhchelvan C., Spectrochim. Acta Part A, 87 (2012), 265.

[25] Subhashini V., Ponnusamy S., Muthamizhchelvan C., J. Cryst. Growth, 363 (2013), 211.

[26] Rajesh B.K.P., Ramasamy P., Mater. Res. Bull., 47 (2012), 2299.

[27] Vetrivel S., AnANDAN P., KanagasabapaTHY K., BhatTaChaRYa S., Gopinath S., RAJASEKARAn R., Spectrochim. Acta Part A, 110 (2013), 317.

[28] Ramasamy B.K.P., Bhagavannarayana G., $J$. Cryst. Growth, 386 (2014), 32. 
[29] Vinoth E., Vetrivel S., Mullai U., Aruljothi R. Gnanamoorthy K., J. Adv. Phys., 7 (2018), 1.

[30] Boopathi B., Bhagavannarayana R.P.G., $J$. Cryst. Growth, 386 (2014), 32.

[31] Caroline M.L., Jayaprakash P., Peer M., J. Mol. Struct., 1134 (2017), 67.

[32] Anis M., Baig M.I., Hussaini S.S., Shirsat M.D., Shkir M., Ghramh H.A., Chinese Physics B, 27 (2018), 47801.

[33] Anis M., Baig M.I., Muley G.G., Shirsat M.D., Shkir M., Ghramh H.A., Mater. Lett., 233 (2018), 238.
[34] Anis M., Muley G.G., Baig M.I., Rabbani G., GHrAmH H.A., Optik, 178 (2019), 752.

[35] Anis M., ShKir M., Baig M.I., Muley G.G., Ramteke S.P., Alfaify S., Ghramh H.A., J. Mol. Struct., 1170 (2018), 151.
Received 2018-08-22

Accepted 2019-07-15 